\title{
Taxonomy of the African large carpenter bees of the genus Xylocopa Latreille, 1802, subgenus Xenoxylocopa Hurd \& Moure, 1963 (Hymenoptera, Apidae)
}

\author{
Jonathan R. Mawdsley' \\ I Department of Entomology, MRC 187, National Museum of Natural History, Smithsonian Institution, P. O. \\ Box 37012, Washington, DC 20013-7012 USA \\ Corresponding author: Jonathan R. Mawdsley (mawdsleyj@si.edu)
}

Academic editor: $M$. Ohl | Received 14 November 2016 | Accepted 27 January 2017 | Published 13 January 2017

http://zoobank.org/ABCFCF8F-60B8-4152-B36B-87F789DD0AAC

Citation: Mawdsley JR (2017) Taxonomy of the African large carpenter bees of the genus Xylocopa Latreille, 1802, subgenus Xenoxylocopa Hurd \& Moure, 1963 (Hymenoptera, Apidae). ZooKeys 655: 131-139. https://doi.org/10.3897/ zookeys.655.11187

\begin{abstract}
The taxonomy of the genus Xylocopa Latreille, 1802, subgenus Xenoxylocopa Hurd \& Moure, 1963, is reviewed. There is a single valid species in this subgenus, Xylocopa (Xenoxylocopa) inconstans Smith, 1874, which is widely distributed throughout sub-Saharan Africa, from Senegal to Ethiopia and south to northern Republic of South Africa. Synonyms of X. inconstans include X. abyssinica Radoszkowski, 1899, proposed for a male specimen from Ethiopia, as well as three names proposed for females with yellow (rather than white) dorsal pubescence: Mesotrichia chiyakensis Cockerell, 1908 (new synonym), X. inconstans var. flavescens Vachal, 1899, and X. inconstans var. flavocincta Friese, 1909. Quantitative analyses of body measurements and examination of male reproductive structures support the new synonymy of Mesotrichia chiyakensis with $X$. inconstans. Males and females of $X$. (X.) inconstans are illustrated, along with male reproductive structures, and diagnostic characters and keys are provided to separate the males and females of X. (X.) inconstans from those of species in other closely-allied African subgenera of the genus Xylocopa.
\end{abstract}

\section{Keywords}

Africa, Apidae, Hymenoptera, identification, Large carpenter bee, pollinator, taxonomy, Xylocopa 


\section{Introduction}

Large carpenter bees, species of the genus Xylocopa Latreille, 1802, are important floral visitors and pollinators of flowering plants in many terrestrial ecosystems, including both agricultural and non-agricultural settings (Hurd and Moure 1963; Gerling et al. 1989; Keasar 2010; Mawdsley et al. 2016). The genus Xylocopa has its greatest diversity in the tropics, with over 700 species currently recognized in the genus (Hurd and Moure 1963; Hurd 1978; Michener 2007). Certain tropical subgenera within the genus Xylocopa are poorly known from a taxonomic viewpoint and in need of revision (Hurd and Moure 1963; Michener 2007). This paper reviews the taxonomic history of a single subgenus, Xylocopa (Xenoxylocopa) Hurd \& Moure, 1963, which occurs throughout much of sub-Saharan Africa.

\section{Taxonomic review}

Hurd and Moure (1963: 243-247) created the subgenus Xenoxylocopa for the reception of five names proposed by earlier authors for African species in the genus Xylocopa Latreille, 1802 (Latreille 1802: 379): X. inconstans Smith, 1874 (Smith 1874: 264), X. abyssinica Radoszkowski, 1899 (Radoszkowski 1899: 127), X. inconstans var. flavescens Vachal, 1899 (Vachal 1899: 146), X. inconstans var. flavocincta Friese, 1909 (Friese 1909: 253), and Mesotrichia chiyakensis Cockerell, 1908 (Cockerell 1908: 34). The type species of the subgenus Xenoxylocopa was fixed by original designation by Hurd and Moure (1963: 243) as Mesotrichia chiyakensis Cockerell.

As noted by Eardley (1983), the taxonomy of species in this subgenus has been based largely on characters of body size and coloration, particularly the color of the pale pubescence on the mesosoma and metasoma of the females, which ranges from white to bright yellow. The first of the five names in this group to be published was $X$. inconstans Smith, 1874, which was based on an unspecified number of representatives of the female sex from South Africa and from Lake Ngami in present-day Botswana (Eardley 1983). Smith (1874) noted that the specimens available to him for study exhibited considerable variation in size and in coloration, with body length ranging from "ten to twelve lines" (approximately 21 to $30 \mathrm{~mm}$ ) and the color of the lighter pubescence ranging from "snow white" to "bright yellow." Radoszkowski (1899) extended the range of $X$. inconstans northward to Ethiopia, based on examination of an unspecified number of white and black female specimens, and proposed the name $X$. abyssinica for a male specimen from Ethiopia. Vachal (1899) described X. inconstans var. flavescens for specimens from Senegal with yellow setae on the scutellum. Cockerell (1908) described Mesotrichia chiyakensis based on a large-bodied female specimen from "Chiyaka, Benguella, West Africa" (in modern-day Angola) with yellow pubescence on the thorax and abdomen, and provided a key to separate females from those of $X$. inconstans and $X$. flavescens, which he treated as full species in the genus Mesotrichia Westwood, 1838. Friese (1909) reviewed the names published to 
date in this group, treating $X$. abyssinica and $X$. chiyakensis as synonyms of $X$. inconstans and describing a variety $X$. inconstans var. flavocincta for female specimens from multiple localities (Gambia, Togo, Madibura and Kwidjwi on Lake Kivu, and Cheren in Eritrea) with yellow pubescence on the scutellum and abdomen. LeVeque (1928) discussed the taxonomic placement and morphological characters of species in this group, transferred its species from Mesotrichia to Xylocopa on the basis of adult morphological characters, and illustrated the male reproductive structures of a specimen of $X$. chiyakensis which had been collected by members of the American Museum of Natural History's Congo Expedition (Osborn 1919) in what is now the Democratic Republic of the Congo.

The taxonomy of the southern African members of this subgenus was reviewed by Eardley (1983), who placed or confirmed placement of three of the five names proposed in this subgenus (X. abyssinica, X. inconstans var. flavescens, and $X$. inconstans var. flavocincta) as synonyms of a single variable species, Xylocopa (Xenoxylocopa) inconstans, based on his study of primary type specimens. Eardley (1983) provided a redescription and illustrations of $X$. inconstans, including illustrations of male reproductive structures, mapped the distribution of this species in southern Africa, and provided keys and diagnostic characters for separating adults of both sexes of $X$. inconstans from the other southern African species of the genus Xylocopa.

Following the work of Eardley (1983), only two species names are recognized in Xylocopa subgenus Xenoxylocopa: $X$. (X.) inconstans and X. (X.) chiyakensis. The most recent subgeneric classification of the genus Xylocopa, that of Michener (2007), treated Xenoxylocopa as a valid subgenus within Xylocopa. Michener (2007) also provided keys for the separation of representatives of the subgenus Xenoxylocopa from those of other subgenera in the genus Xylocopa.

\section{Material examined}

The author recently had the opportunity to study the large collection of African carpenter bees in the U. S. National Museum of Natural History (USNM), assembled by the late P. Hurd. This collection includes a small series ( 2 males, 4 females) of $X$. (X.) chiyakensis which had been collected during the Congo Expedition of the American Museum of Natural History. These specimens formed part of the larger series of specimens that had originally been studied by LeVeque (1928) in the only significant study of $X$. chiyakensis following its description, and all specimens bore LeVeque's handwritten identification labels. This series included the male specimen and accompanying reproductive structures which had been dissected and illustrated by LeVeque (1928).

The USNM material also included 41 specimens of $X$. (X.) inconstans collected at the following localities throughout the species' range: Botswana: Kasane; Democratic Republic of the Congo: Faradje, Garamba, Katanga, Murowe, Park Upemba; Ethiopia: Awasa, Jimma, Lanyani, Melka; Kenya: Stony Athi; Malawi: Southeast shore of Lake Malawi, between Fort Maguire and Fort Johnston; Mozambique: Massangena; 
Namibia: Shamvura, Kavango Province; Niger: 26 miles W Tapoa; Nigeria: Olokenji, Ibadan; Republic of South Africa: Kruger National Park, Skukuza; Tanzania: Iringa, Mbeya, Nandete; Zambia: Mbala; Zimbabwe: Harare.

To test the assertion of Cockerell (1908) that female specimens with yellow pubescence have larger body size than females with white pubescence, a set of basic body measurements (head capsule width, total body length, and right forewing length) were recorded for all female specimens examined. Average values of these measurements were then calculated separately for female specimens with yellow dorsal pubescence and for female specimens with white dorsal pubescence.

Male reproductive structures from specimens collected in association with females of each color form (yellow and white) were also examined, including the dissected structures which had been illustrated by LeVeque (1928).

\section{Results}

\section{Status of Xylocopa (Xenoxylocopa) chiyakensis}

As noted above, Eardley (1983) reviewed the taxonomic status of all names included in Xylocopa subgenus Xenoxylocopa by Hurd and Moure (1963) except X. chiyakensis, which was described from material collected in Angola outside the geographic scope of Eardley's study. The name X. chiyakensis (Cockerell, 1908) has been applied by authors including LeVeque (1928) and Hurd and Moure (1963) to large-bodied female carpenter bees belonging to Xylocopa subgenus Xenoxylocopa which have yellow (as opposed to white) pubescence on the sides of the mesosoma, the scutellum, and the base of the metasoma. However, the material of this subgenus in USNM also includes both small-bodied females with yellow pubescence and large-bodied females with white pubescence, suggesting that the color characters provided by Cockerell (1908) may not actually correlate with the body size characters.

Cockerell (1908) used total body length and forewing length as diagnostic characters in a key to separate his Mesotrichia chiyakensis (said to have total body length 30 $\mathrm{mm}$ and forewing length $26 \mathrm{~mm}$ ) from $X$. inconstans (said to have total body length of $26 \mathrm{~mm}$ and forewing length $21-23 \mathrm{~mm}$ ). In the material examined, females with yellow pubescence $(\mathrm{n}=7)$ had an average head capsule width of $9.1 \mathrm{~mm}$ (range 8.2-10.0 $\mathrm{mm})$ while females with white pubescence $(\mathrm{n}=17)$ had an average head capsule width of $9.0 \mathrm{~mm}$ (range $8.0-10.2 \mathrm{~mm}$ ). Females with yellow pubescence had an average total body length of $27.6 \mathrm{~mm}$ (range $24.5-30.0 \mathrm{~mm}$ ) while females with white pubescence had an average total body length of $25.3 \mathrm{~mm}$ (range 19.8-29.0 mm). Females with yellow dorsal pubescence had an average right forewing length of $24.7 \mathrm{~mm}$ (range $21.8-30.0 \mathrm{~mm}$ ) while females with white dorsal pubescence had an average right forewing length of $24.0 \mathrm{~mm}$ (range $21.0-30.0 \mathrm{~mm}$ ).

Given the significant overlap in these sets of measurements between female specimens with yellow pubescence and female specimens with white pubescence, and the 
fact that the averages of these measurements differ by just $0.1 \mathrm{~mm}$ (average head capsule width), $2.3 \mathrm{~mm}$ (average total body length), and $0.7 \mathrm{~mm}$ (average right forewing length), it does not appear that female specimens with yellow pubescence and female specimens with white pubescence differ significantly in these measurements of body size. Thus, the use of female body size to separate $X$. chiyakensis and $X$. inconstans, as proposed in the key of Cockerell (1908), does not appear to be tenable.

Male reproductive structures of X. chiyakensis were illustrated by LeVeque (1928) and those of $X$. inconstans were illustrated by Eardley (1983). Given the significant differences in size and style of these authors' illustrations, it is difficult to tell from a comparison of these illustrations alone whether significant diagnostic differences are actually present. For this study, I examined the original dissection prepared by LeVeque (1928) from which her line drawing of the male genitalia of X. chiyakensis was derived. From my examination of this dissection, it is clear that the illustration provided by LeVeque (1928) shows the male genital capsule rotated slightly, suggesting that the dissected parts were likely drawn with a camera lucida or similar device, and thus the outline and general appearance of these structures may not be strictly comparable to the illustrations provided by Eardley (1983). Furthermore, the broad lines and small overall size of the illustration provided by LeVeque (1928) actually obscure important structural features of the genital capsule. Accordingly, I have provided a new, photographic image of the dorsal and ventral surfaces of this dissected male genital capsule here (Figure 4). Comparison with my own dissections of $X$. inconstans male reproductive structures from other localities and comparison with the illustrations provided by Eardley (1983) of the male reproductive structures in $X$. inconstans do not reveal significant differences between male reproductive structures in these two forms.

LeVeque (1928) mentioned that the male specimens available to her of X. chiyakensis from central Africa had slightly darker and more brownish pubescence than the male of $X$. inconstans, which she knew only from the description by Radoszkowski (1876). Differences in coloration can provide important diagnostic information at the species level for males of Xylocopa species (see, for example, Eardley 1983 and Hurd 1978). However, the male specimens that I examined from LeVeque's material had evidently been immersed in some preservative prior to pinning, as their pubescence is matted and discolored. This may be the source of the reported color variation, as the male specimens that I examined from northern Zambia and southwestern Tanzania all had lighter colored pubescence which is similar in color to that of males from southern Africa and Ethiopia.

Finally, Eardley (1983) presents compelling evidence that females with yellow pubescence and females with white pubescence are both present in southern African populations of $X$. inconstans, and that in at least one instance females of the two different color forms were even found within the same nest.

Given this combined evidence, and the lack of clear, reliable diagnostic features which could be used to separate $X$. chiyakensis and $X$. inconstans, I have no difficulties in placing $X$. chiyakensis in synonymy with $X$. inconstans, new synonymy. Given the fact that the original description of $X$. inconstans by Smith (1874) emphasized both the body size variation and the color variation that occurs among females of the species, it 
is frankly difficult to understand how and why the yellow female color form was subsequently given three separate Latin names by three different workers.

The full synonymy for this species is therefore as follows:

Xylocopa inconstans Smith, 1874

Xylocopa abyssinica Radoszkowski, 1876

Xylocopa inconstans var. flavescens Vachal, 1899

Mesotrichia chiyakensis Cockerell, 1908, new synonym

Xylocopa inconstans var. flavocincta Friese, 1909

\section{Separation of species of the subgenus Xenoxylocopa from those of other African subgenera of the genus Xylocopa}

Females and males of the subgenus Xenoxylocopa can be readily separated from species in the other African subgenera of the genus Xylocopa using combinations of adult external morphological characters. Females and males of the widespread subgenus Koptortosoma Gribodo, 1894 are most similar to the species of subgenus Xenoxylocopa in terms of their overall appearance and coloration in both males and females (Hurd and Moure 1963). In my experience and that of my colleagues (Mawdsley et al. 2016), certain common and widespread species of the subgenus Koptortosoma are often found in association with the species of the subgenus Xenoxylocopa; however, species of these two subgenera can be readily separated using certain combinations of adult external morphological characters. In particular, the following characters will help to separate species of Xenoxylocopa from sympatric species in the closely allied subgenera Koptortosoma and Mesotrichia Westwood, 1838.

Female (Figures 1, 2). Head capsule broad and massive, space behind eyes greatly expanded. The space behind eyes is not greatly expanded and the head capsule is not as broad and massive in females of subgenera Koptortosoma and Mesotrichia.

First metasomal tergite lacking a distinct invaginated acarinarium or "mite chamber." The acarinarium is present in females of subgenera Koptortosoma and Mesotrichia.

Small tooth present on either side of the median pygidial spine. This tooth is absent in females of subgenera Koptortosoma and Mesotrichia.

Male (Figures 3, 4). Frons very broad, maximum distance between compound eyes across frons greater than the vertical length of the compound eyes. The frons is narrower in males of subgenera Koptortosoma and Mesotrichia.

Inner margin of compound eyes with a distinct groove parallel to and adjacent to the eye margin. This groove is absent in males of subgenera Koptortosoma and Mesotrichia.

\section{Key to subgenera of Xylocopa in the "Mesotrichia group" from Continental Africa}

Michener (2007) provides keys for separating species of subgenus Xenoxylocopa from the other Old World subgenera of Xylocopa, while Eardley (1983) provides keys for separation of both sexes of $X$. inconstans from the other species of Xylocopa in southern Africa. 

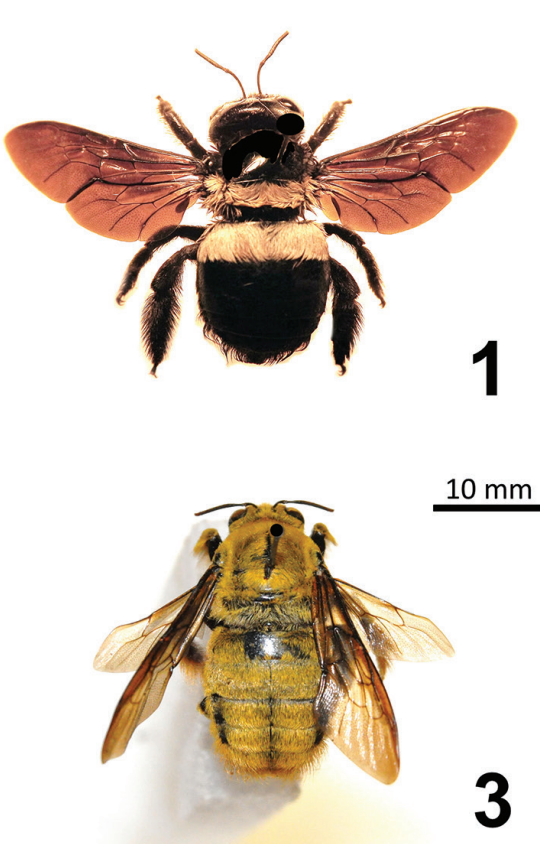
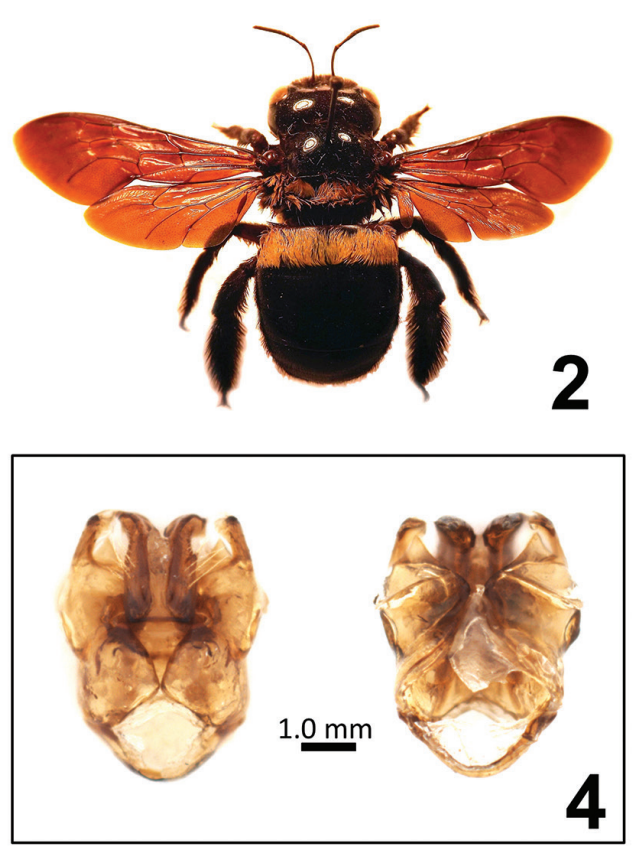

Figure 1-4. I Adult female of Xylocopa (Xenoxylocopa) inconstans Smith, collected by the author at Skukuza, Kruger National Park, Mpumalanga, Republic of South Africa, on flowers of Peltophorum africanum Sonder (Fabaceae) 2 Adult female of Xylocopa (Xenoxylocopa) inconstans Smith, collected at Garamba, Democratic Republic of the Congo, and identified by Norma LeVeque as X. chiyakensis (Cockerell) 3 Adult male of Xylocopa (Xenoxylocopa) inconstans Smith, collected at Kruger National Park, Mpumalanga, Republic of South Africa 4 Dorsal (left) and ventral (right) views of the male genital capsule of $X y$ locopa (Xenoxylocopa) inconstans Smith, collected at Faradje, Democratic Republic of the Congo, dissected and illustrated by Norma LeVeque (1928, figure 16) as the male genitalia of X. chiyakensis (Cockerell).

At this writing, the Michener (2007) keys and text are available online at: http://base. dnsgb.com.ua/files/book/Agriculture/Beekeeping/Thep-Bees-of-the-World.pdf.

The following keys were developed to separate species of the subgenus Xenoxylocopa from species of continental African subgenera which belong to what I call here the "Mesotrichia Group," a morphologically well-defined group of Old World subgenera within Xylocopa which may ultimately prove to be a distinct monophyletic group (as suggested by the phylogenetic analyses of Minckley (1998)). Females of the continental African species in this group can be readily separated from those of other continental African Xylocopa subgenera by the presence of a sharp transverse ridge on the scutellum which divides the scutellum into two distinct surfaces, a more or less horizontal dorsal anterior surface and a more or less vertical posterior surface. Males of the continental African species in this group of subgenera have a somewhat similar modification to the first metasomal tergite, which is divided by a transverse ridge into a more or less horizontal posterior surface and a more or less vertical or sloping anterior surface. In other continental African subgenera of Xylocopa, the scutellum is rounded or feebly angled in females, while the first metasomal tergite is sloping or rounded 
in males. The following key is based on adult morphological characters which were originally identified and used in keys by Hurd and Moure (1963), Eardley (1983), and Michener (2007), and which were confirmed through my own examination of specimens of these subgenera in USNM.

1 Antenna with 10 flagellomeres, metatibiae with two tibial spurs, sting apparatus present, pygidial plate present, females ..............................................2

- $\quad$ Antenna with 11 flagellomeres, metatibiae with one tibial spur, sting apparatus absent, pygidial plate absent, males ....................................................... 4

2 First metasomal tergite lacking a distinct invaginated acarinarium or "mite chamber," head capsule greatly enlarged and massive, pygidium with a small tooth on either side of the median pygidial spine .... Xylocopa (Xenoxylocopa)

- $\quad$ First metasomal tergite with distinct invaginated acarinarium or "mite chamber," head capsule not greatly enlarged, pygidium lacking small tooth on either side of the median pygidial spine ........................................................ 3

3 Elevated ridge of scutellum extending beyond posterior margin of metanotum.................................................................... Xylocopa (Koptortosoma)

- $\quad$ Elevated ridge of scutellum not extending beyond posterior margin of metanotum Xylocopa (Mesotrichia)

4 Mesothoracic legs strongly modified, with spines and/or flattened areas........ Xylocopa (Mesotrichia)

- $\quad$ Mesothoracic legs not strongly modified ...................................................5

5 Frons very broad, maximum distance between compound eyes across frons greater than the vertical length of the compound eyes; inner margin of compound eyes with a distinct groove parallel to and adjacent to the eye margin....

Xylocopa (Xenoxylocopa)

- $\quad$ Frons narrower, maximum distance between compound eyes across frons less than the vertical length of the compound eyes; inner margin of compound eyes lacking a distinct groove parallel to and adjacent to the eye margin

Xylocopa (Koptortosoma)

\section{Acknowledgements}

I thank S. Brady and B. Harris for providing me with the opportunity to study specimens of Xylocopa subgenus Xenoxylocopa in the collections of the U. S. National Museum of Natural History, Smithsonian Institution. For permission to collect specimens of $X$. inconstans and other insect taxa in the Kruger National Park, I thank F. Venter of South African National Parks. I also thank my colleagues H. Sithole of South African National Parks and J. Harrison of the University of the Witwatersrand for their gracious assistance in the field. Two external peer reviewers, C. Eardley and S. van Noort, provided valuable comments during the peer review process that greatly improved the manuscript. I thank M. Ohl for coordination of the peer review process for this manuscript. 


\section{References}

Cockerell TDA (1908) Some bees collected by Dr. F. C. Wellman in West Africa. Entomologist 41: 34-36.

Eardley CD (1983) A taxonomic revision of the genus Xylocopa Latreille (Hymenoptera: Anthophoridae) in southern Africa. Entomology Memoir, Department of Agriculture, Republic of South Africa 58: 1-67.

Friese H (1909) Die Bienen Afrikas nach dem Stande unserer heutigen Kenntnisse. Denkschriften der Medicinisch-Naturwissenschaftlichen Gesellschaft zu Jena 14: 83-476.

Gerling D, Velthuis HHW, Hefetz A (1989) Bionomics of the large carpenter bees of the genus Xylocopa. Annual Review of Entomology 34: 163-190. https://doi.org/10.1146/annurev. en.34.010189.001115

Hurd PD (1978) An Annotated Catalog of the Carpenter Bees (Genus Xylocopa Latreille) of the Western Hemisphere (Hymenoptera: Anthophoridae). Smithsonian Institution Press, Washington, DC, 106 pp.

Hurd PD, Moure JS (1963) A classification of the large carpenter bees (Xylocopini) (Hymenoptera: Apoidea). University of California Publications in Entomology 29: 1-365.

Keasar T (2010) Large carpenter bees as agricultural pollinators. Psyche 2010: 1-7. https://doi. org/10.1155/2010/927463

Latreille P (1802) Histoire naturelle, générale et particulière, des crustacés et des insectes, tome troisiéme. L'imprimerie de F. Dufart, Paris, 467 pp.

LeVeque N (1928) Carpenter bees of the genus Mesotrichia obtained by the American Museum Congo Expedition, 1909-1915. American Museum Novitates 300: 1-23.

Mawdsley J, Harrison J, Sithole H (2016) Natural history of a South African insect pollinator assemblage (Insecta: Coleoptera, Diptera, Hymenoptera, Lepidoptera): diagnostic notes, food web analysis and conservation recommendations. Journal of Natural History. https:// doi.org/10.1080/00222933.2016.1216194

Michener CD (2007) The Bees of the World ( $2^{\text {nd }}$ edn). Johns Hopkins University Press, Baltimore, $992 \mathrm{pp}$.

Minckley RL (1998) A cladistic analysis and classification of the subgenera and genera of the large carpenter bees, tribe Xylocopini (Hymenoptera: Apidae). Scientific Papers, Natural History Museum, University of Kansas 9: 1-47. https://doi.org/10.5962/bhl.title.16168

Osborn HF (1919) The Congo Expedition of the American Museum of Natural History. Bulletin of the American Museum of Natural History 39: 15-28. https://doi.org/10.5962/bhl. title. 53716

Radoszkowski O (1876) Compte-rendu des Hyménoptères recueillis en Egypte et Abyssinie en 1873. Trudy Russkago Entomologicheskago Obshchestva 12: 111-150.

Smith F (1874) Monograph of the genus Xylocopa Latr. Transactions of the Entomological Society of London 1874: 247-302.

Vachal J (1899) Matériaux pour une révision des espèces africaines du genre Xylocopa Latr. Annales de la Société Entomologique de France 67: 92-99. 